\title{
Prevalence of asymptomatic deep vein thrombosis in patients hospitalized with SARS-CoV-2 pneumonia: a cross-sectional study
}

\author{
Matteo Giorgi-Pierfranceschi ${ }^{1}$ (1) - Oriana Paoletti ${ }^{2} \cdot$ Angelo Pan $^{3} \cdot$ Fabio De Gennaro $^{1} \cdot$ Anna Laura Nardecchia $^{1}$. \\ Rossella Morandini ${ }^{2}$. Claudia Dellanoce ${ }^{2}$ - Samuele Lombi ${ }^{1} \cdot$ Maurizio Tala $^{2}$. Vanessa Cancelli ${ }^{2} \cdot$ Silvia Zambelli $^{2}$. \\ Giancarlo Bosio ${ }^{4}$. Laura Romanini ${ }^{5}$. Sophie Testa ${ }^{2}$
}

Received: 16 May 2020 / Accepted: 5 August 2020 / Published online: 25 August 2020

(c) Società Italiana di Medicina Interna (SIMI) 2020

\begin{abstract}
The association between coronavirus disease 2019 (COVID-19) pneumonia and venous thrombotic disorders is still unclear. We assessed the association between COVID-19 infection-related pneumonia and proximal deep-vein thrombosis (DVT) in a cohort of patients admitted to our hospital during the European outbreak in the front line of Cremona, Lombardy. In a single-center cross-sectional study, all patients hospitalized for more than 5 days in Internal Medicine Department with confirmed COVID-19 pneumonia received 2-point compressive ultrasound assessment (CUS) of the leg vein system during a single day. Ninety-four percent of patients received enoxaparin as standard pharmacological prophylaxis for venous thromboembolism. The presence of DVT was defined as incompressibility of popliteal or common femoral vein. Out of 121 patients with COVID-19 pneumonia (mean age 71.8, 66.3\% males) hospitalized on March 31st, 70 stayed in hospital for over 5 days and 66 of them underwent CUS of deep venous system of the legs. The presence of asymptomatic DVT was found in 9 patients (13.6\%). No symptomatic DVT was found. Patients with DVT showed mean age $=75.7$ years, mean D-dimer levels $=4.02 \mathrm{ng} / \mathrm{ml}$ and all of them received enoxaparin for thromboprophylaxis, except one. Computed tomography pulmonary angiogram confirmed pulmonary embolism in five patients. One every seven patients with COVID-19-related pneumonia, hospitalized for more than 5 days, had asymptomatic proximal DVT and half of them had confirmed PE despite standard pharmacological thromboprophylaxis. This observational study suggests the need of an active surveillance through CUS in patients hospitalized with acute SARS-COV-2 and underline the need of a more intense thromboprophylaxis.
\end{abstract}

Keywords Prevalence $\cdot$ Asymptomatic deep veins thrombosis $\cdot$ Covid-19 pneumonia $\cdot$ Point of care ultrasonography

Matteo Giorgi-Pierfranceschi magiopi65@gmail.com

1 Department of Internal Medicine, Hospital of Cremona, Viale Concordia 1, 26100 Cremona, Italy

2 Haemostasis and Thrombosis Center, Hospital of Cremona, Cremona, Italy

3 Department of Infectious Disease, Hospital of Cremona, Cremona, Italy

4 Department of Pneumology, Hospital of Cremona, Cremona, Italy

5 Department of Radiology, Hospital of Cremona, Cremona, Italy

\section{Introduction}

The World Health Organization on March 11th 2020 declared the novel coronavirus infection COVID-19 a global pandemic $[1,2]$. Italy, particularly the area of Cremona located in the northern region, was notified as the first European country where severe acute respiratory syndrome due to COVID-19 (SARS-CoV-2) was spreading [2].

From February 21st until the end of March, 1328 patients were admitted to the Hospital of Cremona with confirmed diagnosis of COVID-19 pneumonia.

As known, patients hospitalized for acute medical illnesses, such as pneumonia, congestive respiratory failure, acute infection, rheumatic disorders, acute arthritis, or inflammatory bowel disease, show an increased risk for venous thromboembolism (VTE). Moreover, prolonged immobilization, the association of other acquired or 
individual risk factor, such as age $>75$ years, cancer, previous venous thromboembolism, obesity or sepsis, further increase thromboembolic risks [3-9].

VTE represents a frequent and potentially fatal complication in hospitalized patients. Pharmacological thromboprophylaxis has shown to significantly reduce VTE events, both in surgical and medical patients, with a relatively low risk of adverse events [9-12].

Evidence-based guidelines recommend use of low-dose parenteral anticoagulants in medically ill patients at high risk for thromboembolism for 6-14 days; while, an extended thromboprophylaxis could be advantageous in patients with additional and persistent risk factors [8, 9, 14]. Standardized thromboprophylaxis in acute medical ill patients include low dose of parenteral drugs such as unfractionated heparin (UH), low-molecular weight heparin (LMWH), or fondaparinux [8-13].

The incidence of VTE in medically ill patients treated with validated dosages of LMWH is nearly $4.4 \%$ [10] but optimization of thromboprophylaxis has been underlined in special settings such as in sepsis and in obese patients [15-18].

Currently, LMWH enoxaparin $40 \mathrm{mg}$ daily represents the standard of care for venous thromboembolism prevention in acute ill patients in our hospital.

Aim of our study was to evaluate the prevalence of deep vein thrombosis of the legs in a cohort of patients admitted to Internal Medicine of Cremona Hospital, with severe
SARS-Cov-2 infection and treated with standard thromboprophylaxis, in a period between 5 and 10 days from hospitalization.

\section{Methods}

\section{Hospital setting}

The study was conducted in the Internal Medicine Department of Cremona Hospital, in Italy. Starting from February 21, 2020, the 550-bed hospital was transformed to admit patients with COVID-19 pneumonia. Patients were hospitalized in four different COVID dedicated areas: Departments of Infectious Disease, Internal Medicine, Pneumology, and Intensive Care Unit. Patients not needing mechanical ventilation were indistinctly admitted to Infectious Disease, Internal Medicine or Pneumology Departments, altogether including four hundred beds.

\section{Study design}

This single-center cross-sectional study was approved by the Local Ethics Committee. Cross-sectional studies are characterized by the collection of relevant data at a given time-point and this study design is the most relevant design when assessing the prevalence of a disease. Flow chart of the study is detailed in Fig. 1.

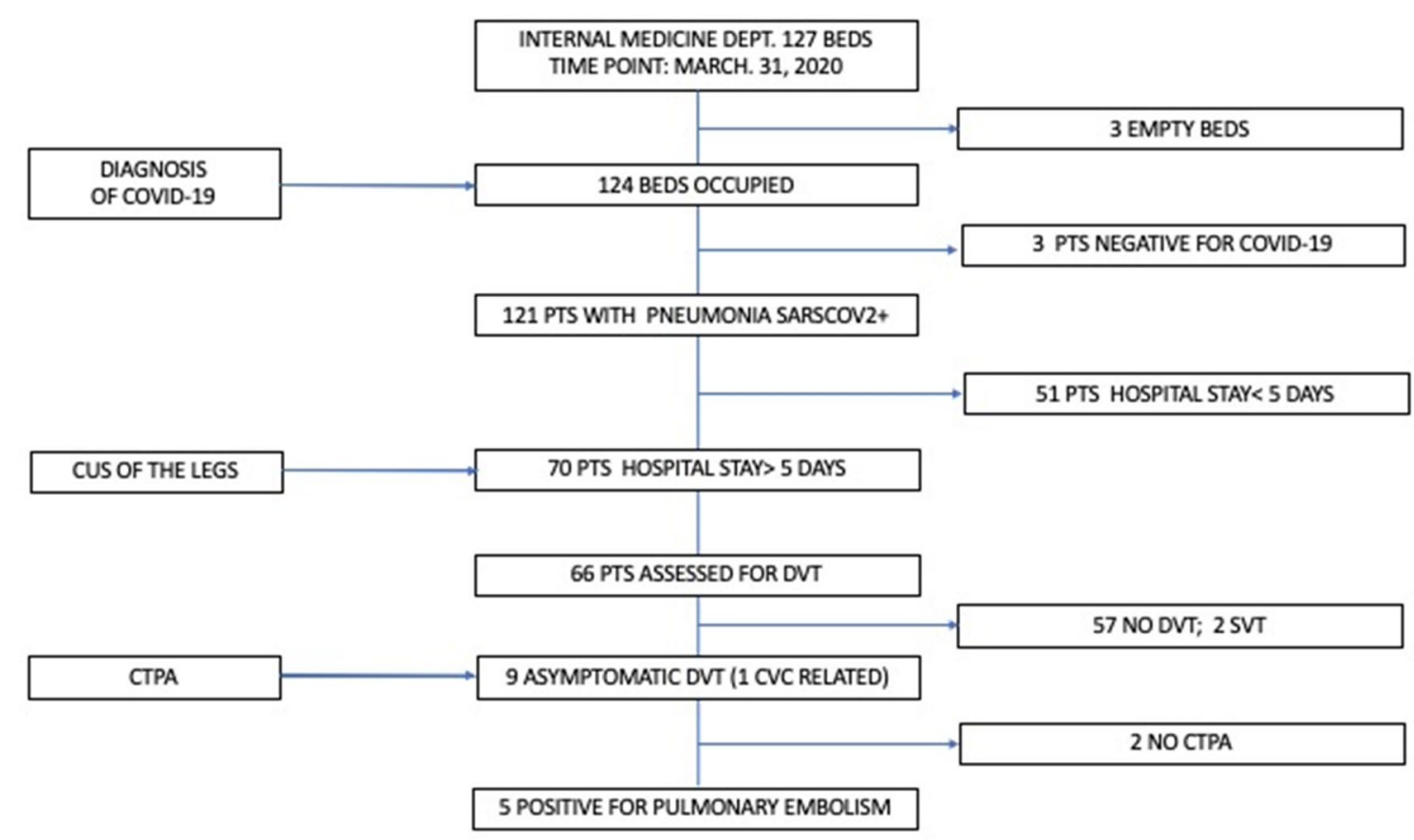

Fig. 1 Flow chart of patients' recruitment. Legend: PTS: patients; CVC: central venous catheter; DVT: deep venous thrombosis; CTPA: computed tomographic pulmonary angiogram; CUS: compressive ultrasound; SVT: superficial vein thrombosis 


\section{Patients}

On admission at the emergency department, all patients underwent high-resolution computed tomography (HRCT) of the lung or chest X-ray to diagnose pneumonia and a standard LMWH prophylaxis (enoxaparin $40 \mathrm{mg}$ daily) was immediately started.

In a single day (May 31, 2020), all patients who had been hospitalized in Internal medicine department for at least 5 days underwent 2-point compressive ultrasonography of the legs regardless of the presence of DVT symptoms.

\section{Patients' data}

The following data were recorded in a structured data-base:

- Demographic, weight, main clinical characteristics such as presence of chronic coexisting diseases, prior VTE, active cancer, in-hospital length of stay (LOS)

- Pharmacological thromboprophylaxis

- Respiratory failure and severity of pneumonia: respiratory failure was diagnosed when arterial blood gas analysis showed arterial partial pressure of oxygen $(\mathrm{PaO} 2)$ less than $60 \mathrm{mmHg}$.

Pneumonia was categorized according to $\mathrm{PaO}_{2}$ and fraction of inspired oxygen $\left(\mathrm{FiO}_{2}\right)$ ratio on admission. Three mutually exclusive categories based on degree of hypoxemia were defined: mild (200-300 $\mathrm{mm} \mathrm{Hg}$ ); moderate (100-199 mm Hg); severe (<100 mm Hg). The attending physician established the need of oxygen and/or C-pap support, case by case. Reduced mobilization was considered as bedrest with bathroom privileges (either due to patient's limitations or on physician's order) for at least 3 days [19, 20].

\section{COVID-19 diagnosis}

Oropharyngeal swabs were obtained on hospital admission. SARS-CoV-2 RNA was searched using commercial RT-PCR methods (ELITechGroup, Paris, France). GeneFinder ${ }^{\text {TM }}$ COVID-19 PlusRealAmp Kit detects Sars-CoV-2 by amplification of RdRp gene, E gene and $\mathrm{N}$ gene according to the WHO recommended protocol [21].

\section{D-dimer assay}

Plasma samples were collected within the first $24 \mathrm{~h}$ from hospitalization in vacuum plastic tubes (Vacutainer, Becton-Dickinson, Plymouth, UK), containing 3.2\% trisodium citrate $(9: 1 \mathrm{vol} / \mathrm{vol}$, blood/anticoagulant), centrifuged within $1 \mathrm{~h}$ from collection at $2000 \mathrm{~g}$ for $15 \mathrm{~min}$ and immediately tested.
D-dimer was assessed using a quantitative method (STA Liatest D-dimer) on STA-R, a fully automated multiparameter coagulometer (Stago, France).

A cut-off below $0.5 \mu \mathrm{g} / \mathrm{ml}$, as recommended by manufacturer for VTE exclusion, was considered as normal plasma level.

\section{Diagnosis of DVT}

Diagnosis of DVT was performed by a two-region ultrasound protocol according to the recommendations from the Society of Radiologists Ultrasound for lower extremity deep venous thrombosis [22]. All eligible patients underwent bedside bilateral proximal lower limb compressive ultra-sound (CUS) performed by physicians with trained experience in vascular ultrasound, using the Mindray DC-70 ultrasound machine with a 7.5-MHz linear probe (Fig. 2). The common femoral vein and the proximal tract of femoral vein were examined first, with the patients lying supine. The popliteal vein to its trifurcation was evaluated with the patients in a (left or right) lateral decubitus or less frequently in the prone position. All compressions were done using B-mode imaging with transverse views by applying compression along the deep venous system of each patient. The diagnostic criterion for DVT was the inability to fully compress the lumen of the vein in the transverse plane [23].

\section{Diagnosis of pulmonary embolism}

Patients with finding of DVT underwent computed tomography pulmonary angiography (CTPA) examination performed using $64 \mathrm{MD}$ GE Revolution Evo equipment, after administration of 60-80 ml of non-ionic, high-concentration contrast media $(370 \mathrm{mg} / \mathrm{ml})$ followed by $40 \mathrm{ml}$ saline chaser at at $4-6 \mathrm{ml} / \mathrm{s}$. Angiographic images were acquired in the

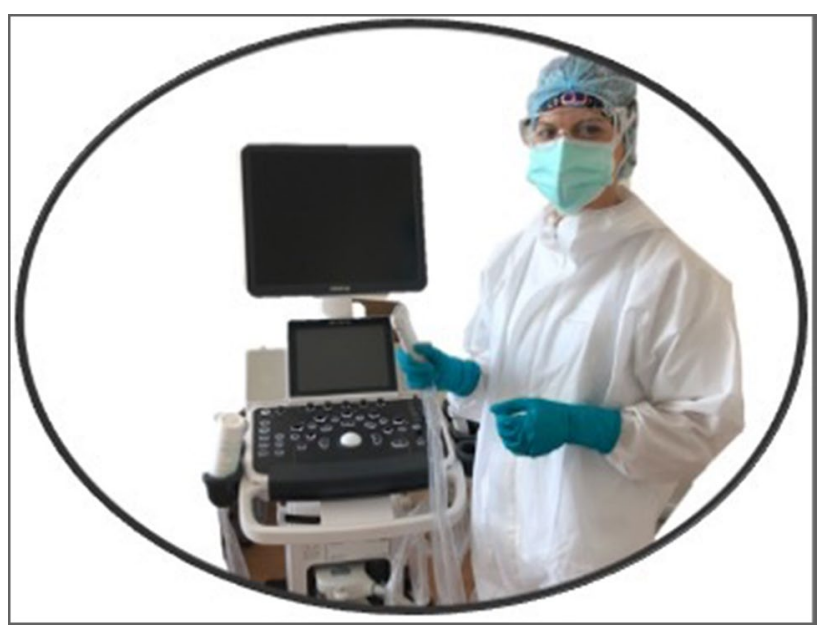

Fig. 2 Point of care US in COVID areas 
supine position and cranio-caudal direction with collimation of $0.6 \mathrm{~mm}$, reconstructed with standard algorithm, and slices thickness and interval of $1.25 \mathrm{~mm}$. CT scans were reviewed by expert radiologist in thoracic imaging.

\section{Thromboprophylaxis}

As per the internal protocol, all the admitted patients with COVID-19-associated pneumonia, received thromboprophylaxis with once-daily subcutaneous administration of a standard dose of enoxaparin $40 \mathrm{mg}$ daily.

\section{Statistical analysis}

Descriptive analysis was performed. Continuous variables are expressed as mean and standard deviation, or median \pm standard deviation (SD) and range. Categorical variables are expressed as frequencies and percentages.

\section{Results}

On March 31st 2020, 70 out of 121 patients with COVID19-associated pneumonia were hospitalized for at least 5 days in the Department of Internal Medicine of the Hospital of Cremona; of them, 66 were included in the analysis, while four patients were not tested due to their absence in the ward at the moment of the test for different procedures.

\section{Overall population}

We scanned 66 patients asymptomatic for DVT from admission to the time point. The mean age was 71.5 years $( \pm 11)$; patients were mostly males (69.6\%). The mean timing of respiratory symptoms onset was 5.1( \pm 4.1$)$ days before hospital admission. Reduced mobilization affected the 59\% of patients. The mean body weight was $77 \mathrm{~kg}( \pm 16)$. Sixty-one $\%$ of the patients had respiratory failure (severe $24 \%$; moderate $37 \%$; mild 6\%). No patient had clinical and laboratory pattern of disseminated intravascular coagulation (mean values of PT was $1.1 \pm 0.1$; aPTT $1.0 \pm 1.45$; fibrinogen $499 \pm 176 \mathrm{mg} / \mathrm{dl}$ ). The mean value of Creatinine clearance was $72.6 \pm 31.8 \mathrm{ml} / \mathrm{min}$, and no patient had values less than $30 \mathrm{ml} / \mathrm{min}$. The mean length of hospital stay (LOS) was 12.6 days $( \pm 5)$. Ninety-four percent of the study population received thromboprophylaxis at admission: 53 patients, enoxaparin $40 \mathrm{mg}$ daily. Nine patients received enoxaparin $60 \mathrm{mg}$ daily because of a perceived higher risk of thrombosis by the attending physician. Five patients were not treated with LMWH because of thrombocytopenia and recent history of bleedings (Table 1). None of the scanned patients had symptoms of DVT.
Table 1 Main demographic and clinical characteristics of the study population

\begin{tabular}{|c|c|c|}
\hline Features & $\begin{array}{l}\text { Admitted } \\
\text { patients } \\
(n=121)\end{array}$ & $\begin{array}{l}\text { Scanned } \\
\text { patients } \\
(n=66)\end{array}$ \\
\hline Age $($ mean $\pm S D)$ years & $71.8 \pm 12$ & $71.5 \pm 11$ \\
\hline Male sex $(\%)$ & $77(66.3 \%)$ & $46(69.6 \%)$ \\
\hline Body weight (mean $\pm \mathrm{SD}$ ) $\mathrm{kg}$ & $77.1( \pm 17)$ & $77( \pm 16)$ \\
\hline \multicolumn{3}{|l|}{ Mobilization } \\
\hline Yes & $58(48 \%)$ & $27(41 \%)$ \\
\hline No & $53(44 \%)$ & $39(59 \%)$ \\
\hline Unknown & $10(8 \%)$ & 0 \\
\hline \multicolumn{3}{|l|}{ Lenght of hospital stay } \\
\hline (Mean days $\pm \mathrm{SD}$ ) & $8.3( \pm 6.5)$ & $12.6( \pm 5)$ \\
\hline \multicolumn{3}{|l|}{ Clinical history } \\
\hline Hypertension & $38(31 \%)$ & $22(33 \%)$ \\
\hline Other disease & $18(15 \%)$ & $6(9 \%)$ \\
\hline Diabetes & $17(14 \%)$ & $9(13 \%)$ \\
\hline Asthma/COPD & $16(13 \%)$ & $8(12 \%)$ \\
\hline CAD & $12(10 \%)$ & $7(10 \%)$ \\
\hline Cancer & $11(9 \%)$ & $6(9 \%)$ \\
\hline CKD & $11(9 \%)$ & $4(6 \%)$ \\
\hline Other cardiac diseases & $11(9 \%)$ & $8(12 \%)$ \\
\hline Atrial fibrillation & $8(6 \%)$ & $3(4 \%)$ \\
\hline Obesity & $8(6 \%)$ & $3(4 \%)$ \\
\hline TIA/stroke & $7(7 \%)$ & $5(7 \%)$ \\
\hline Previous VTE & $4(3 \%)$ & $1(1 \%)$ \\
\hline Haemorrhages & $2(2 \%)$ & 0 \\
\hline \multicolumn{3}{|l|}{ Clinical characteristics } \\
\hline Confirmed COVID-19 pneumonia & $121(100 \%)$ & $66(100 \%)$ \\
\hline Respiratory failure $\mathrm{PaO}_{2}<60 \mathrm{mmHg}$ & $74(61 \%)$ & $45(68 \%)$ \\
\hline $\mathrm{P} / \mathrm{F}<100$ & $25(20 \%)$ & $16(24 \%)$ \\
\hline P/F 100-200 & $37(30 \%)$ & $25(37 \%)$ \\
\hline $\mathrm{P} / \mathrm{F} 200-300$ & $12(10 \%)$ & $4(6 \%)$ \\
\hline \multicolumn{3}{|l|}{ D-Dimer $(\mu \mathrm{g} / \mathrm{ml})$} \\
\hline D-dimer $($ mean $\pm \mathrm{SD})$ & $3.25( \pm 5.2)$ & $3.29( \pm 4.6)$ \\
\hline $\begin{array}{l}\text { D-dimer in DVT patients } \\
(\text { mean } \pm \text { SD })\end{array}$ & $4.02( \pm 3.55)$ & \\
\hline \multicolumn{3}{|l|}{ Enoxaparin daily dose } \\
\hline $40 \mathrm{mg}$ & 107 & 53 \\
\hline $60 \mathrm{mg}$ & 9 & 9 \\
\hline No prophyalxis & 5 & 4 \\
\hline
\end{tabular}

$\mathrm{PaO}_{2}$ : arterial partial pressure of oxygen, $\mathrm{FiO} 2$ : fraction of inspired oxygen, $\mathrm{P} / \mathrm{F}$ ratio: $\mathrm{PaO} 2 / \mathrm{FiO} 2$, DVT: deep vein thrombosis

Among 66 patients, a proximal DVT was confirmed in 9 patients (13.6\%), and ruled out in 57 patients; of them, 2 patients without varices had superficial venous thrombosis (SVT). In patients with finding of DVT, a CTPA was performed. Seven patients of nine were scanned; two patients did not undergo the test because of their critical condition. 
Pulmonary embolism (PE) was confirmed in five cases, as shown in Fig. 1.

\section{DVT population}

Nine patients had proximal asymptomatic DVT. The mean age was $75.7( \pm 12)$ years, LOS was $13.8( \pm 6)$ days, they were all males, and the mean body weight was $78( \pm 14)$. Eight out of nine patients had mobility limitations. Only one of them had mild pneumonia, while 8 out of 9 had moderate to severe respiratory failure (4 moderate; 4 severe; $5 / 9$ needed c-pap support). All patients had asymptomatic proximal DVT, bilateral in 3 cases. One patient had a prior DVT. One DVT was catheter associated. CTPA was assessed in seven patients and PE was confirmed in five of them (7.5\% of the analyzed patients).

The main demographic and clinical characteristics of the patients with DVT are shown in Table 2

\section{Discussion}

Our study shows that in patients admitted to a hospital medical ward because of COVID-19-associated pneumonia, the prevalence of silent proximal DVT was as high as $13.6 \%$, despite standard anticoagulant prophylaxis. This finding could partially explain the high incidence of pulmonary embolism described in previous study and autoptic series $[24,25]$. Furthermore, DVT was frequently bilateral and it was found only in male patients; similarly, a higher prevalence in male subjects has been reported even in a previous study in non-ICU patients [26]. The novel coronavirus COVID-19 is causing hospitalization of thousands of patients with pneumonia admitted for severe respiratory syndrome [1, 2, 27, 28]. At hospitalization, patients are managed in relation to severity of respiratory distress and general clinical conditions and admitted to ICU or clinical wards.

Acute medical illness, such as congestive heart failure or respiratory failure, from long time are recognized as clinical conditions at high risk for venous thromboembolism $[8,9]$ and standardized parenteral low-dose anticoagulant drugs are recommended and enoxaparin $40 \mathrm{mg}$ daily represents the most commonly adopted regimen in our country.

Patients admitted to Cremona Hospital with COVID-19 are usually treated, in the absence of contraindications such as severe thrombocytopenia, renal impairment, or active bleeding, with standard dose of enoxaparin $40 \mathrm{mg}$ daily for VTE prevention, independent of age and weight.

Our observational study aimed to evaluate the prevalence of asymptomatic DVT in COVID-19 hospitalized patients, treated with the standard regimen of prophylactic LMWH.

Patients were frequently bedridden (59\%) with respiratory failure $(68 \%)$ and, in this specific clinical condition in which respiratory distress is the main persistent symptom associated with decreased $\mathrm{PaO}_{2}$, other causes of possible impairment, other than COVID-19 pneumonia, could have been easily overlooked. Furthermore, patients may have also a reduced reactivity to promptly refer symptoms suggestive for DVT that, in any case, should be always confirmed through radiological exams due to poor specificity of clinical signs [29].

This high prevalence of asymptomatic DVT patients, even with a standard thromboprophylaxis, poses us a crucial question: how and when to suspect VTE in this particular medical condition? Previous studies showed the high mortality rate in patients hospitalized with acute medical illness with asymptomatic proximal DVT [30, 31].

Since prevalence of VTE in this study population treated with standard dose of LMWH is as high as that observed in the absence of prophylaxis in medical patients [10], we can suppose that it should be even higher without a pharmacological prevention.

Peculiar characteristics of this viral infection can cause prolonged immobilization, possible dehydration, a massive inflammatory response of the organism that in more severe cases may evolve towards acute respiratory distress syndrome (ARDS), severe coagulopathy and multi-organ failure, all conditions that increase thromboembolic complications. This condition can be associated with increased risks with the need of higher doses of heparin thromboprophylaxis as previously suggested [10, 18, 32-37]; furthermore, acquired antithrombin deficiencies may also occur in these clinical situations, thus causing heparin resistance [38, 39].

The role of D-Dimer in relation to VTE diagnosis in this study population deserves a special consideration. As shown in Tables 1 and 2, high D-Dimer levels have been measured in all patients, despite the result of CUS. Therefore, in this setting, on one hand D-Dimer showed a poor usefulness in relation to its high negative predictive value; whereas, on the other, its correlation between elevated D-Dimer levels and VTE should be better investigated and specific cut-off defined [35, 40-45].

Waiting for further data regarding the proper use of D-Dimer in this clinical condition and based on currently evidences, we consider that early surveillance could be reasonable to promptly avoid DVT complications.

As stated before, the importance of this first study, conducted in hospitalized COVID-19 patients is the evidence of a high prevalence of asymptomatic DVT, despite a standard anticoagulant prophylaxis. On this basis, in our opinion, three important elements should be kept into consideration to properly define the global VTE risk of each single patient in addition to acute infectious disease: (a) Individual risk factors, such as age, weight, sex, cancer, history of previous VTE, that independently increase thromboembolic risk; (b) time of disease onset and time of bed rest and 


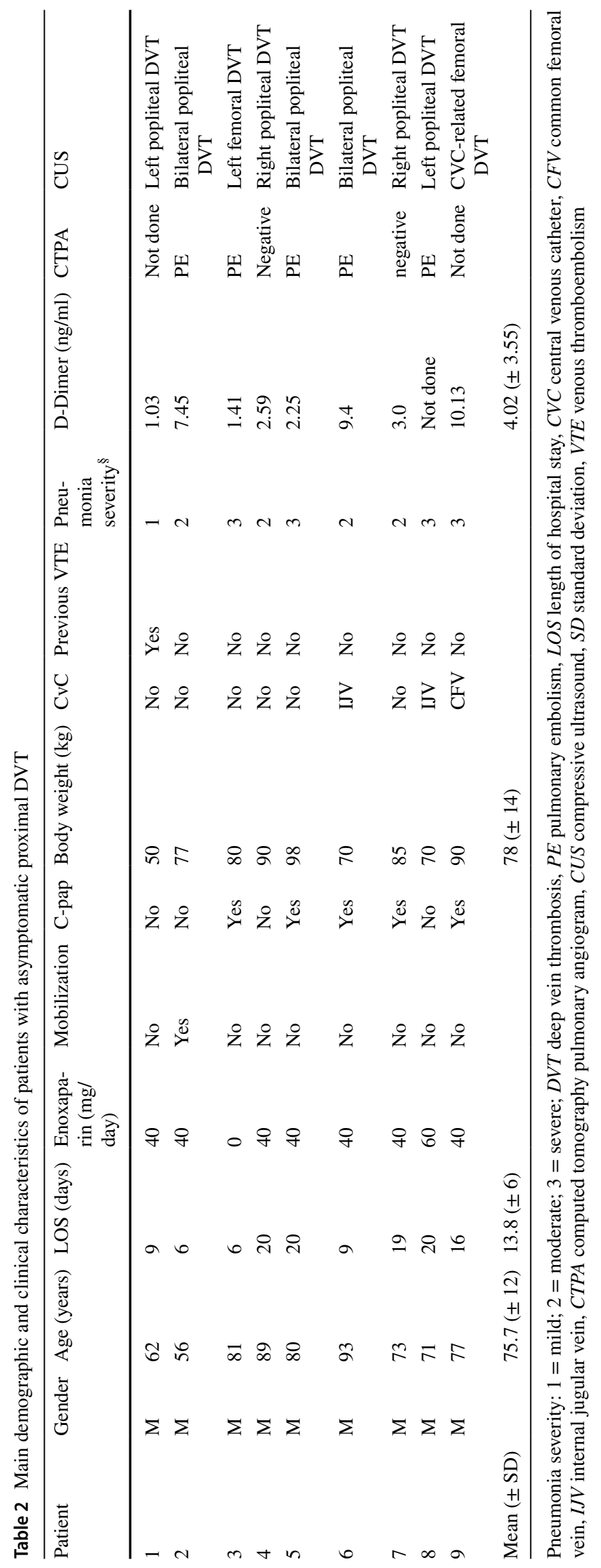


immobilization, to promptly start LMWH prophylaxis; (c) posology of heparin, that should be increased to reach the correct prophylaxis range which may not be "a fixed dose for all", as already proposed in patients with sepsis [18, 32-34].

For the above considerations and highlighting the very high thromboembolic risks of hospitalized COVID-19 patients on standard prophylaxis, we conclude that: (a) routinely compressive ultrasound of the legs should be performed during the first week of hospitalization; (b) LMWH prophylaxis should be started immediately at the onset of acute COVID-19 pneumonia; (c) LMWH prophylaxis should be ensured to all patients, adapting doses in relation to weight, renal function with the target to maintaining upper levels of prophylactic range $(\mathrm{aXa}=0.2-0.5 \mathrm{UI} / \mathrm{ml})[35,36]$.

\section{Study limitation}

This study presents several limitations due to its monocenter design and the relatively small sample size; however, it represents the first evidence of the high prevalence of asymptomatic DVT in patients hospitalized with COVID-19 pneumonia, outside intensive care units and despite standard prophylactic dose of LMWH.

Probably, our data underestimated occurrence of DVT, first because we studied only patients with LOS more than 5 days without knowing the right time of the onset of the disease and the mobility limitation before hospitalization.

Second, in our protocol, we use a point of care ultrasound, widely used also in the medical wards [46] consisting of a two-point CUS evaluation that may underestimates the presence of isolated femoral DVT and does not look at all for calf DVT [47, 48].

Finally, based on the high frequency of both DVT and PE despite standard anticoagulant prophylaxis, an important knowledge gap remains regarding the optimal time for CUS examination during and after hospital discharge, as well as the optimal LMWH prophylactic treatment and its duration.

\section{Conclusions}

Our observation highlights the high prevalence of asymptomatic proximal DVT in patients hospitalized with COVID-19 pneumonia and the need to implement appropriate active patient surveillance strategies using ultrasound, as well as the adoption of adequate pharmacological thromboprophylaxis.

These findings may have prognostic implications, but larger dedicated studies are warranted.

Author contributions MG-P and ST designed the study, collected all data, wrote and revised the draft. They had full access to all of the data in the study and takes responsibility for the integrity of the data and the accuracy of the data analysis. Acquisition, analysis, or interpretation of data, revision of the manuscript: all authors. MG-P, ST: Drafting of the manuscript. Critical revision of the manuscript for important intellectual content: all authors. MG-P, ST: statistical analysis and supervision.

\section{Compliance with ethical standards}

Conflict of interest All authors have no conflict of interest.

Ethics approval Ethics committee approval was requested.

Informed consent No informed consent was requested beacuse of compressive ultrasound is a standard of care.

\section{References}

1. Phelan AL, Katz R, Gostin LO (2020) The novel coronavirus originating in Wuhan, China: Challenges for Global Health Governance. JAMA. https://doi.org/10.1001/jama.2020.1097

2. World Health Organization (WHO) (2020) Coronavirus disease 2019 (COVID-19) Situation Report - 51, 2020

3. Heit JA, Melton LJ, Lohse CM et al (2001) Incidence of venous thromboembolism in hospitalized patients vs community residents. Mayo Clin Proc 76(11):1102-1110

4. Bahl V et al (2010) A validation study of a retrospective venous thromboembolism risk scoring method. Ann Surg 251:344-350

5. Cohen AT, Alikhan R, Arcelus JI, Bergmann JF, Haas S, Merli GJ, Spyropoulos AC, Tapson VF, Turpie AG (2005) Assessment of venous thromboembolism risk and the benefits of thromboprophylaxis in medical patients. Thromb Haemost 94(4):750-759

6. Alikhan R, Cohen AT, Combe S, Samama MM, Desjardins L, Eldor A, Janbon C, Leizorovicz A, Olsson CG, Turpie AG, MEDENOX Study (2004) Risk factors for venous thromboembolism in hospitalized patients with acute medical illness: analysis of the MEDENOX Study. Arch Intern Med 164(9):963-968

7. Dentali F, Douketis JD, Gianni M, Lim W, Crowther MA (2007) Meta-analysis: anticoagulant prophylaxis to prevent symptomatic venous thromboembolism in hospitalized medical patients. Ann Intern Med 146(4):278-288

8. Kahn SR, Lim W, Dunn AS, Cushman M, Dentali F, Akl EA, Cook DJ, Balekian AA, Klein RC, Le H, Schulman S, Murad MH (2012) Prevention of VTE in nonsurgical patients: antithrombotic therapy and prevention of thrombosis, 9th ed: American College of Chest Physicians Evidence-Based Clinical Practice Guidelines. Chest 141(2 Suppl):e195S-e226S

9. Schünemann HJ, Cushman M, Burnett AE, Kahn SR, Beyer-Westendorf J, Spencer FA, Rezende SM, Zakai NA, Bauer KA, Dentali F, Lansing J, Balduzzi S, Darzi A, Morgano GP, Neumann I, Nieuwlaat R, Yepes-Nuñez JJ, Zhang Y, Wiercioch W (2018) American Society of Hematology 2018 guidelines for management of venous thromboembolism: prophylaxis for hospitalized and nonhospitalized medical patients. Blood Adv 2(22):3198-3225

10. Samama MM, Cohen AT, Darmon JY, Desjardins L, Eldor A, Janbon C, Leizorovicz A, Nguyen H, Olsson CG, Turpie AG, Weisslinger N (1999) A comparison of enoxaparin with placebo for the prevention of venous thromboembolism in acutely ill medical patients. Prophylaxis in Medical Patients with Enoxaparin Study Group. N Engl J Med 341(11):793-800

11. Leizorovicz A, Cohen AT, Turpie AG, Olsson CG, Vaitkus PT, Goldhaber SZ, PREVENT Medical Thromboprophylaxis Study Group (2004) Randomized, placebo-controlled trial of 
dalteparin for the prevention of venous thromboembolism in acutely ill medical patients. Circulation 110(7):874-879

12. Cohen AT, Davidson BL, Gallus AS, Lassen MR, Prins MH, Tomkowski W, Turpie AG, Egberts JF, Lensing AW, Investigators ARTEMIS (2006) Efficacy and safety of fondaparinux for the prevention of venous thromboembolism in older acute medical patients: randomized placebo-controlled trial. BMJ 332(7537):325-329

13. Mahan CE, Pini M, Spyropoulos AC (2010) Venous thromboembolism prophylaxis with unfractionated heparin in the hospitalized medical patient: the case for thrice daily over twice daily dosing. Intern Emerg Med 5:299-306

14. Amin AN, Varker H, Princic N, Lin J, Thompson S, Johnston S (2012) Duration of venous thromboembolism risk across a continuum in medically ill hospitalized patients. J Hosp Med 7(3):231-238

15. Vandiver JW, Ritz LI, Lalama JT (2016) Chemical prophylaxis to prevent venous thromboembolism in morbid obesity: literature review and dosing recommendations. J Thromb Thrombolysis 41(3):475-481

16. Boonyawat K, Crowther MA (2015) Venous thromboembolism prophylaxis in critically ill patients. Semin Thromb Hemost 41(1):68-74

17. Minet C, Potton L, Bonadona A, Hamidfar-Roy R, Somohano CA, Lugosi M, Cartier JC, Ferretti G, Schwebel C, Timsit JF (2015) Venous thromboembolism in the ICU: main characteristics, diagnosis and thromboprophylaxis. Crit Care 19:287

18. Kaplan D, Casper TC, Elliott CG, Men S, Pendleton RC, Kraiss LW, Weyrich AS, Grissom CK, Zimmerman GA, Rondina MT (2015) VTE incidence and risk factors in patients with severe sepsis and septic shock. Chest 148(5):1224-1230

19. Barbar S, Noventa F, Rossetto V, Ferrari A, Brandolin B, Perlati M, De Bon E, Tormene D, Pagnan A, Prandoni P (2010) A risk assessment model for the identification of hospitalized medical patients at risk for venous thromboembolism: the Padua Prediction Score. J Thromb Haemost 8(11):2450-2457

20. Barbar S, Prandoni P (2017) Scoring systems for estimating risk of venous thromboembolism in hospitalized medical patients. Semin Thromb Hemost 43(5):460-468

21. Laboratory testing for 2019 novel coronavirus (2019-nCoV) in suspected human cases Interim guidance, 19 March 2020. Publication WHO REFERENCE NUMBER: WHO/COVID19/laboratory/2020.5. https://www.who.int/publications-detai 1/laboratory-testing-for-2019-novel-coronavirus-in-suspectedhuman-cases-20200117

22. Needleman L, Cronan JJ, Lilly MP, Merli GJ, Adhikari S, Hertzberg BS, DeJong MR, Meissner MH, Streiff MB (2018) Ultrasound for lower extremity deep venous thrombosis: multidisciplinary recommendations from the society of radiologists in ultrasound consensus conference. Circulation 137(14):1505-1515

23. Lensing AWA, Prandoni P, Brandjes D, Huisman PM, Vigo M, Tomasella $G$ et al (1989) Detection of deep-vein thrombosis by real-time B-mode ultrasonography. N Engl J Med 320:342-345

24. Klok FA, Kruip MJHA, van der Meer NJM, Arbous MS, Gommers DAMPJ, Kant KM, Kaptein FHJ, van Paassen J, Stals MAM, Huisman MV, Endeman H (2020) Incidence of thrombotic complications in critically ill ICU patients with COVID-19. Thromb Res 20(20):30120-30121

25. Wichmann D, Sperhake JP, Lütgehetmann M, et al. (2020) Autopsy findings and venous thromboembolism in patients with COVID-19 [published online ahead of print, 2020 May 6]. Ann Intern Med, M20-2003

26. Artifoni M, Danic G, Gautier G et al (2020) Systematic assessment of venous thromboembolism in COVID-19 patients receiving thromboprophylaxis: incidence and role of D-dimer as predictive factors. J Thromb Thrombolysis 50(1):211-216. https ://doi.org/10.1007/s11239-020-02146-Z

27. Lai CC, Shih TP, Ko WC, Tang HJ, Hsueh PR (2020) Severe acute respiratory syndrome coronavirus 2 (SARS-CoV-2) and coronavirus disease-2019 (COVID-19): the epidemic and the challenges. Int J Antimicrob Agents 55(3):105924

28. Huang C, Wang Y, Li X, Ren L, Zhao J, Hu Y, Zhang L, Fan G, Xu J, Gu X, Cheng Z, Yu T, Xia J, Wei Y, Wu W, Xie X, Yin W, Li H, Liu M, Xiao Y, Gao H, Guo L, Xie J, Wang G, Jiang R, Gao Z, Jin Q, Wang J, Cao B (2020) Clinical features of patients infected with 2019 novel coronavirus in Wuhan, China. Lance. 395(10223):497-506

29. Cogo A, Lensing AW, Koopman MM, Piovella F, Siragusa S, Wells PS, Villalta S, Büller HR, Turpie AG, Prandoni P (1998) Compression ultrasonography for diagnostic management of patients with clinically suspected deep vein thrombosis: prospective cohort study. BMJ 316(7124):17-20

30. Vaitkus PT, Leizorovicz A, Cohen AT, Turpie AG, Olsson CG, Goldhaber SZ (2005) Prevent Medical Thromboprophylaxis Study Group, Mortality rates and risk factors for asymptomatic deep vein thrombosis in medical patients. Thromb Haemost 93(1):76-79

31. Zhou Fei, Ting Yu, Ronghui Du, Fan Guohui, Liu Ying, Liu Zhibo, Xiang Jie, Wang Yeming, Song Bin, XiaoyingGu Lulu Guan, Wei Yuan, Li Hui, Xudong Wu, Jiuyang Xu, ShengjinTu Yi Zhang, Chen Hua, Cao Bin (2020) Clinical course and risk factors for mortality of adult inpatients with COVID-19 in Wuhan, China: a retrospective cohort study. Lancet 395:1054-1062

32. Obi AT, Tignanelli CJ, Jacobs BN, Arya S, Park PK, Wakefield TW, Henke PK, Napolitano LM (2019) Empirical systemic anticoagulation is associated with decreased venous thromboembolism in critically ill influenza A H1N1 acute respiratory distress syndrome patients. J Vasc Surg Venous Lymphat Disord 7(3):317-324

33. Poli D, Tosetto A, Palareti G et al (2020) Managing anticoagulation in the COVID-19 era between lockdown and reopening phases. Intern Emerg Med. https://doi.org/10.1007/s11739-02002391-3

34. Testa S, Paoletti O, Giorgi-Pierfranceschi M et al (2020) Switch from oral anticoagulants to parenteral heparin in SARS-CoV-2 hospitalized patients. Intern Emerg Med. https://doi.org/10.1007/ s11739-020-02331-1

35. Wang T, Chen R, Liu C et al (2020) Attention should be paid to venous thromboembolism prophylaxis in the management of COVID-19. Lancet Haematol. 7(5):e362-e363

36. Johnston A, Hsieh SC, Carrier M, Kelly SE, Bai Z, Skidmore B, Wells GA (2018) A systematic review of clinical practice guidelines on the use of low molecular weight heparin and fondaparinux for the treatment and prevention of venous thromboembolism: implications for research and policy decision-making. PLoS ONE 13(11):e0207410

37. Smythe MA, Priziola J, Dobesh PP, Wirth D, Cuker A, Wittkowsky AK (2016) Guidance for the practical management of the heparin anticoagulants in the treatment of venous thromboembolism. J Thromb Thrombolysis 41(1):165-186

38. Anderson JA, Saenko EL (2002) Heparin resistance. Br J Anaesth 88(4):467-469

39. Girolami A, Cosi E, Ferrari S, Girolami B (2018) Heparin, coumarin, protein $\mathrm{C}$, antithrombin, fibrinolysis and other clotting related resistances: old and new concepts in blood coagulation. $\mathrm{J}$ Thromb Thrombolysis 45(1):135-141

40. Manfredini R (2006) D-dimer for the diagnosis of acute venous thromboembolism in the emergency department: a Janus-face marker. Int Emergency Med 1:54

41. Chen T, Wu D, Chen H, Yan W, Yang D, Chen G, Ma K, Xu D, Yu H, Wang H, Wang T, Guo W, Chen J, Ding C, Zhang X, Huang J, Han M, Li S, Luo X, Zhao J, Ning Q (2020) Clinical 
characteristics of 113 deceased patients with coronavirus disease 2019: retrospective study. BMJ 368:m1091

42. Terpos E, Ntanasis-Stathopoulos I, Elalamy I et al (2020) Hematological findings and complications of COVID-19. Am J Hematol 95(7):834-847

43. Lim W, Le Gal G, Bates SM, Righini M, Haramati LB, Lang E, Kline JA, ChasteenS Snyder M, Patel P, Bhatt M, Patel P, Braun C, Begum H, Wiercioch W, Schünemann HJ, Mustafa RA (2018) American Society of Hematology 2018 guidelines for management of venous thromboembolism: diagnosis of venous thromboembolism. Blood Adv. 2(22):3226-3256

44. Linkins LA, Takach Lapner S (2017) Review of D-dimer testing: good, bad, and ugly. Int J Lab Hematol. 39(Suppl 1):98-103

45. Rodger MA, Le Gal G, Wells P, Baglin T, Aujesky D, Righini M, Palareti G, Huisman M, Meyer G (2014) Clinical decision rules and D-Dimer in venous thromboembolism: current controversies and future research priorities. Thromb Res 134(4):763-768

46. Leidi A, Rouyer F, Marti C, Reny JL, Grosgurin O (2020) Point of care ultrasonography from the emergency department to the internal medicine ward: current trends and perspectives. Intern Emerg Med 15(3):395-408. https://doi.org/10.1007/s11739-02002284-5

47. Adhikari S, Zeger W, Thom C, Fields JM (2015) Isolated deep venous thrombosis: implications for 2-point compression ultrasonography of the lower extremity. Ann Emerg Med 66:262-266. https://doi.org/10.1016/j.annemergmed.2014.10.032

48. Frederick MG, Hertzberg BS, Kliewer MA, Paulson EK, Bowie JD, Lalouche KJ, DeLong DM, Carroll BA (1996) Can the US examination for lower extremity deep venous thrombosis be abbreviated? A prospective study of 755 examinations. Radiology 199:45-47. https://doi.org/10.1148/radiology.199.1.8633171

Publisher's Note Springer Nature remains neutral with regard to jurisdictional claims in published maps and institutional affiliations. 